\title{
Does the Green Great Wall effectively decrease dust storm intensity in China? A study based on NOAA NDVI and weather station data
}

\author{
Minghong Tan*, Xiubin Li \\ Key Laboratory of Land Surface Pattern and Simulation, Institute of Geographic Sciences and Natural Resources Research (IGSNRR), \\ Chinese Academy of Sciences (CAS), Beijing 100101, PR China
}

\section{A R T I C L E I N F O}

\section{Article history:}

Received 7 July 2014

Received in revised form

15 September 2014

Accepted 22 October 2014

\section{Keywords:}

Green Great Wall

NDVI

Dust storm intensity

\begin{abstract}
A B S T R A C T
China launched its "Green Great Wall" (GGW) program in 1978. However, the effects of this program are subject to intense debate. This study compares changes in the vegetation index in regions where the GGW program has been implemented with those where it has not. Subsequently, a definition to measure dust storm intensity (DSI) was proposed that better calculates the intensity of dust events; it considers the frequency, visibility, and duration of dust events. The results show that in the GGW region, vegetation has greatly improved, while it varied dramatically outside the GGW region. In the mid-1980s, DSI decreased significantly, different from the changes in dust storm frequency in the study region. By discounting the effects of climatic change and human pressures, the results show that the GGW program greatly improved the vegetation index and effectively reduced DSI in northern China.
\end{abstract}

(c) 2014 Elsevier Ltd. All rights reserved.

\section{Introduction}

Dust has a considerable impact on aerosol radioactive forcing, biogeochemical cycling, and agricultural production. This impact often affects vast areas (Prospero, 1999; Prospero and Lamb, 2003; Schepanski et al., 2012). For instance, sand and dust from east and central Asia are not only carried to Japan, North Korea, and South Korea across the sea, but can also influence the Pacific Ocean and even be transported to North America and Greenland (McKendry et al., 2001; Huang et al., 2007; Uno et al., 2009; Wang et al., 2013). Thus, many countries have instituted anti-desertification programs at a national level, such as Iran's National Action Program to Combat Desertification (Amiraslani and Dragovich, 2011), the Country Pilot Partnership for Integrated Sustainable Land Management in Namibia (Akhtar-schuster et al., 2011), the 22nd Country Master Plan in Israel (Portnov and Safriel, 2004), and the Great Plains Shelterbelt project in the United States. Of these, perhaps the most famous is the Great Plains Shelterbelt, which stretches over $29,000 \mathrm{~km}$ in a $160 \mathrm{~km}$-wide zone from Canada to the Brazos River in the eastern Great Plains (Cook and Cable, 1995). However, the outcomes following the implementation of these programs have spurred intense international debate (McTainsh et al., 2011),

\footnotetext{
* Corresponding author. Tel.: +86 10 64889431; fax: +86 1064854230 .

E-mail address: tanmh@igsnrr.ac.cn (M. Tan).
}

with many observers concluding that they have been ineffective as desertification controls worldwide (Glenna et al., 1998).

China's desert areas, which occupy approximately $13 \%$ of the country's total surface area, are a major source of Asian dust (Song, 2004). In a bid to improve broader environmental factors as well as to combat desertification, the Chinese Government has implemented several ecological restoration projects including the Grain for Green (GFG) program (Feng et al., 2003; Wang et al., 2007), the Green Great Wall (GGW) program (Fang et al., 2001), and the Natural Forest Conservation program (Zhang et al., 2000). Among them, the GGW program is arguably one of the most aggressive meteorological-modification programs of the 20th century (Parungo et al., 1994). It was designed to curtail the expansion of the Gobi Desert and will, ultimately, cover 4.1 million $\mathrm{km}^{2}$. Also called the Three-North Shelterbelt Forest Program, it will represent the dominant ecological engineering program in China and account for an important portion of the world's total ecological construction (Wang et al., 2010). The GGW program was launched in 1978 and is to be completed by 2050 .

In light of this information, has the implementation of the GGW program brought about the desired effect of dampening dust storms in China? Some authors consider the project to have been successful, pointing to the fact that the forest cover rate has increased from 5.1\% in 1978 to $9.0 \%$ in 2001 (Zhu et al., 2004), and that vegetation conditions have improved (Duan et al., 2011). Both of these factors control desertification and may decrease dust storm frequency (DSF), especially in the MuUs and Horqin sand lands 
of China. Conversely, other studies conclude that the program's effectiveness at controlling dust storms should be questioned (Wang et al., 2010) because decreases in DSF are caused mainly by climatic factors. Therefore, before a more rigorous evaluation of the effects of the implemented GGW program on dust storm intensity (DSI) can be carried out, we must resolve two fundamental issues. First, can we prove that the changes in vegetation resulted from the implementation of the program rather than from natural conditions such as precipitation? Second, a more accurate definition with which to measure dust storm activities is required because DSF cannot fully reflect DSI, which has a close relationship with the frequency, visibility, and duration of dust events (McTainsh et al., 2005; Speer, 2013; O'Loingsigh et al., 2014).

In this study, we compare changes in the vegetation indices for the regions where the GGW program has been implemented ("GGW region") with those for where it has not ("Outside GGW region"; Fig. 1). Moreover, the effects of precipitation on the vegetation indices are also taken into account. Next, we calculate DSI with reference to duration, visibility, and frequency. Finally, we evaluate the effects of the implementation of the GGW program on DSI.

\section{Study area}

The study area covers 6.9 million $\mathrm{km}^{2}$ and ranges from approximately $23^{\circ} 52^{\prime}$ to $53^{\circ} 31^{\prime} \mathrm{N}$ and from $73^{\circ} 29^{\prime}$ to $134^{\circ} 58^{\prime} \mathrm{E}$ (Fig. 1). In this area, the main vegetation types include farmland, grass, forest, desert, and no vegetation. The main soil types include aeolian, calcic, desert, meadow, cinnamon, and brown earth soils.

The study area includes two parts: the GGW region and the Outside GGW region (Fig. 1). The GGW region includes 551 counties in 13 provinces, municipalities and autonomous regions in northern China; it stretches from far-western Xinjiang to Heilongjiang in the northeast, representing approximately $42 \%$ of the total land area of the country. In this region, mean annual precipitation varies from approximately $450 \mathrm{~mm}$ in the southeastern part to $20 \mathrm{~mm}$ in the northwestern part (Zheng and Zhu, 2013).

\section{Data and methods}

Dust storm data (from 1971 to 1998) were sourced from the China Meteorological Administration and included the start and end times of the dust storm, visibility details, and the geographic location of each observation station (longitude and latitude). In China, before 1979 , storm events were rated on a scale of '0' to ' 9 ' by meteorological observation stations, mainly according to visibility range; however, the visibility was not recorded. Since 1980, visibility data has been recorded at all stations. Following the pre-1979 criterion, this study first classified the dust events after 1979 into ten grades. Subsequently, the mid value of the visibility for each grade was used to calculate the DSI (Table 1). Based on the availability of dust event data from 1971 to 1998,142 stations were selected for use in this study.

Various vegetation indices have been used to monitor changes in vegetation. The indices from brightness values are based on the differential absorption, transmittance, and reflectance of energy by the vegetation in the red and near-infrared portions of the electromagnetic spectrum (Senay and Elliott, 2000). Among indices, the normalized difference vegetation index (NDVI) provides a clear description of land surface features and is often regarded as a proxy for terrestrial vegetation growth because it is strongly correlated with leaf area index, potential photosynthesis, and above ground net primacy productivity (Holm et al., 2003; Piao et al., 2011). In this study, NDVI remote sensing data were obtained from the Advanced Very High Resolution Radiometer (AVHRR) of the
Table 1

The visibility range denoted for every level (pre-1979 criterion).

\begin{tabular}{llc}
\hline Grade & Visibility $(\mathrm{m})$ & $\begin{array}{c}\text { Mid-value of } \\
\text { visibility }(\mathrm{m})^{\mathrm{a}}\end{array}$ \\
\hline 0 & $<50$ & 25 \\
1 & $\geq 50$ to $<200$ & 125 \\
2 & $\geq 200$ to $<500$ & 350 \\
3 & $\geq 500$ to $<1000$ & 750 \\
4 & $\geq 1000$ to $<2000$ & 1500 \\
5 & $\geq 2000$ to $<4000$ & 3000 \\
6 & $\geq 4000$ to $<10,000$ & 7000 \\
7 & $\geq 10,000$ to $<20,000$ & 15000 \\
8 & $\geq 20,000$ to $<50,000$ & 35000 \\
9 & $\geq 50,000$ & 50000 \\
\hline
\end{tabular}

a Note: Visibility is used in the calculation of DSI.

National Oceanic and Atmospheric Administration (NOAA). The NDVI value consists of bi-weekly composite images with 8-km resolutions. This data has been widely applied in semi-arid and arid areas (Anyamba and Tucker, 2005; Fensholt et al., 2012; Funk and Brown, 2006; Holm et al., 2003) because the data are in good agreement with ground-based observations (Holm et al., 2003; Fensholt et al., 2009). Therefore, the AVHRR NDVI data set is well suited for vegetation studies, especially in regions with an annual rainfall less than $1000 \mathrm{~mm}$, such as the Sahel-Sudanian area (Fensholt et al., 2009).

\section{Definition of DSI}

We calculated the summed DSIs $\left(\mathrm{SDSI}_{j}\right)$ of all dust events recorded by a station in year $j$ using Eq. (1) (Tan et al., 2014):

$\operatorname{SDSI}_{j}=\sum_{i=1}^{n}\left(\operatorname{DURA}_{i}^{j} \times \frac{1}{\operatorname{VISIB}_{i}^{j}}\right)$

where $\operatorname{DURA}_{i}^{j}$ is the duration of dust event $i$ at the station in year $j$ calculated according to the start and end times of the dust event, and $\operatorname{VISIB}_{i}^{j}$ is the visibility (in meters) of dust event $i$ at the station in year $j$.

We then further calculated the total value (T_SDSI) of SDSI $_{j}$ for all years at a station using the following Eq. (2):

T_SDSI $=\sum_{j=1}^{k} \operatorname{SDSI}_{j}$

In 1999, another afforestation initiative-the GFG program-was launched in China; it is difficult to distinguish the effects of the GGW program from those of the GFG initiative. Thus, our study encompasses the period from 1971 to 1998 to discuss the effects of the GGW program on DSI. Furthermore, in north China, the NDVI increased from April to October, while lower temperatures and higher altitudes created a shorter growing season (July and August) in the western and northern plateau areas (Duan et al., 2011). Hence, our study selected the average NDVI for July and August as representative of the growing season.

\section{Results and discussion}

\section{Changes in DSI values}

Based on Eq. (1), we obtained the summed SDSI values across all 142 meteorological observation stations for each year (Fig. 2). Between 1971 and 1984, the DSI varied greatly; since 1985, it has decreased dramatically. This conclusion differs from the trend observed in DSF, which has decreased continuously since 1971 (Fig. 2), as confirmed by existing literature (Wang et al., 2010). 


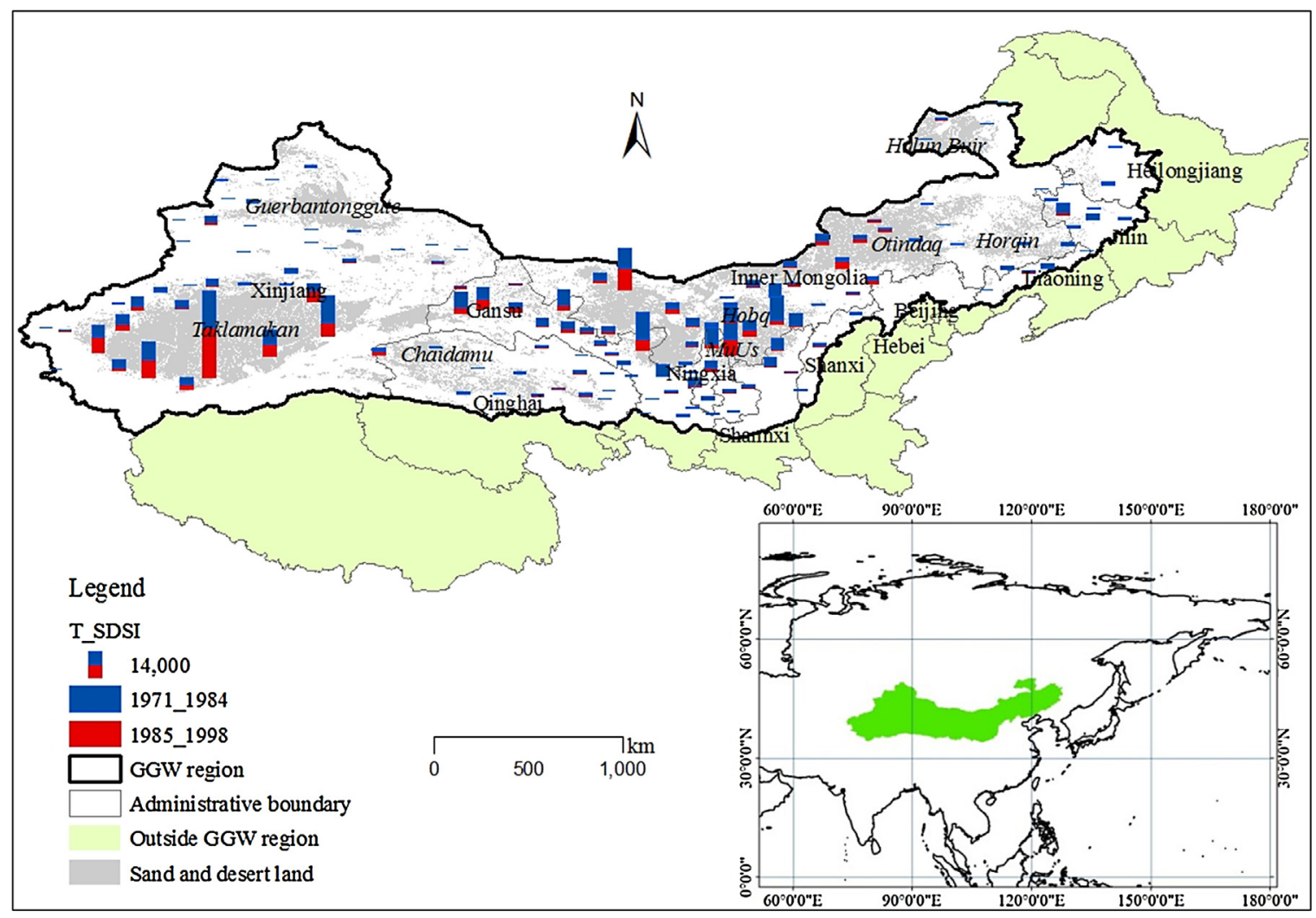

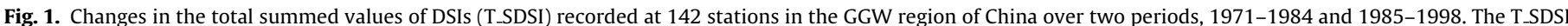

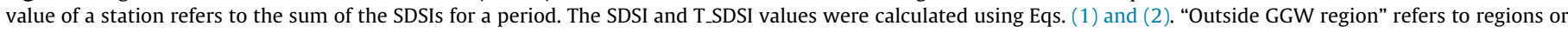
provinces where the GGW program was not implemented that experienced dust activities.

To identify the spatiotemporal changes in DSI values at the selected stations in more detail, we divided the study period of 1971-1998 into two equal subperiods: $1971-1984$ and 1985-1998 (Fig. 1). The results show vast spatial differences in the T_SDSI values at the 142 stations during the two subperiods. Higher T_SDSI values were primarily observed in northwestern China around the Taklamakan Desert and in the middle part of Inner Mongolia (Fig. 1). At most stations, the T_SDSI values decreased dramatically from the earlier period to the later one; however, at a few observation sta-

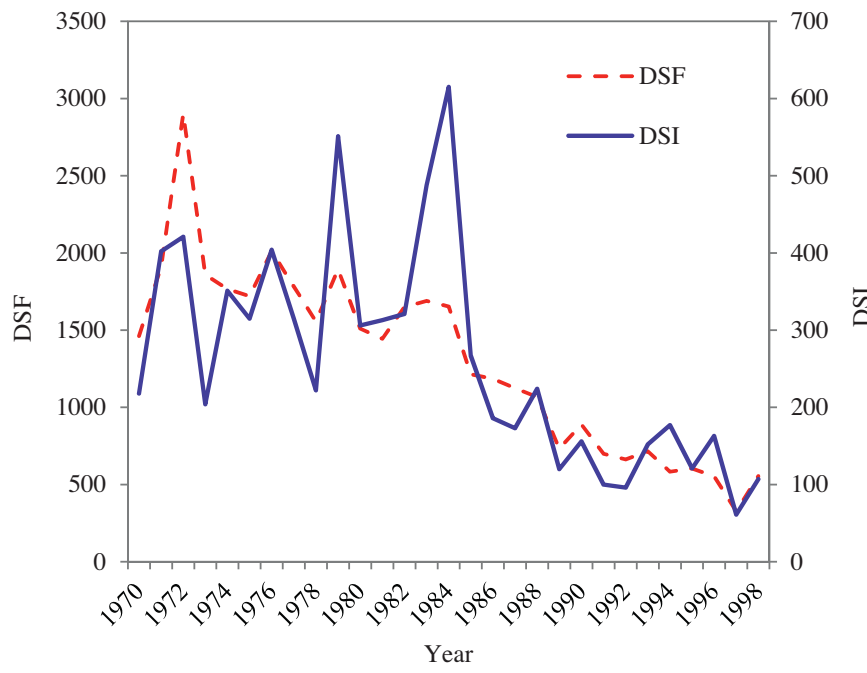

Fig. 2. Changes in the average values of SDSI and DSF (annual days) at 142 stations in the GGW region in China, 1971-1998. tions, the T_SDSI values increased. These stations were located near or in the Otindaq Desert and at the southern edge of the Taklamakan Desert.

\section{Changes in NDVI values inside and outside the GGW region}

We calculated the summer average NDVI values in the study region for every year in the GGW region. The results indicated a trend of increasing NDVI values, similar to that reported in existing literature. To examine this trend in more detail, we further calculated the 3-year average NDVI values within the 1981-1998 study period. Fig. 3 shows that the increasing NDVI trend was highly significant in the GGW region, especially from 1981 to 1992, while the NDVI values varied greatly outside of the GGW region. Therefore, we infer that the implementation of the GGW program improved vegetation density in the GGW region.

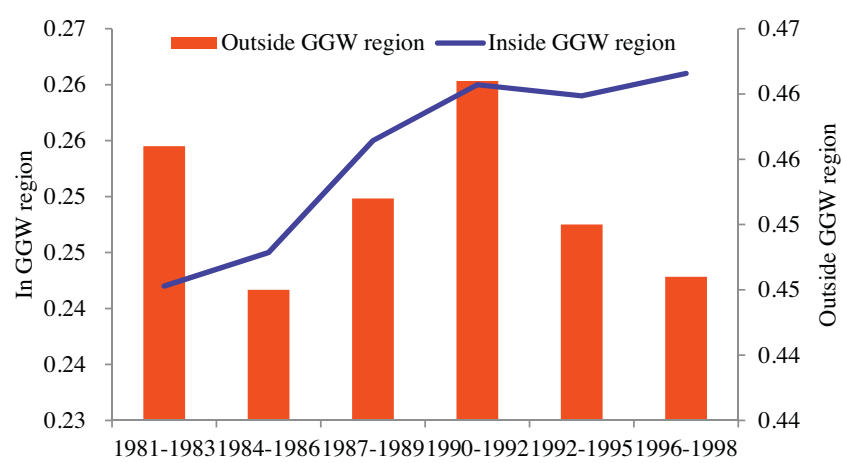

Fig. 3. Average NDVI values during six study subperiods at 142 stations. 

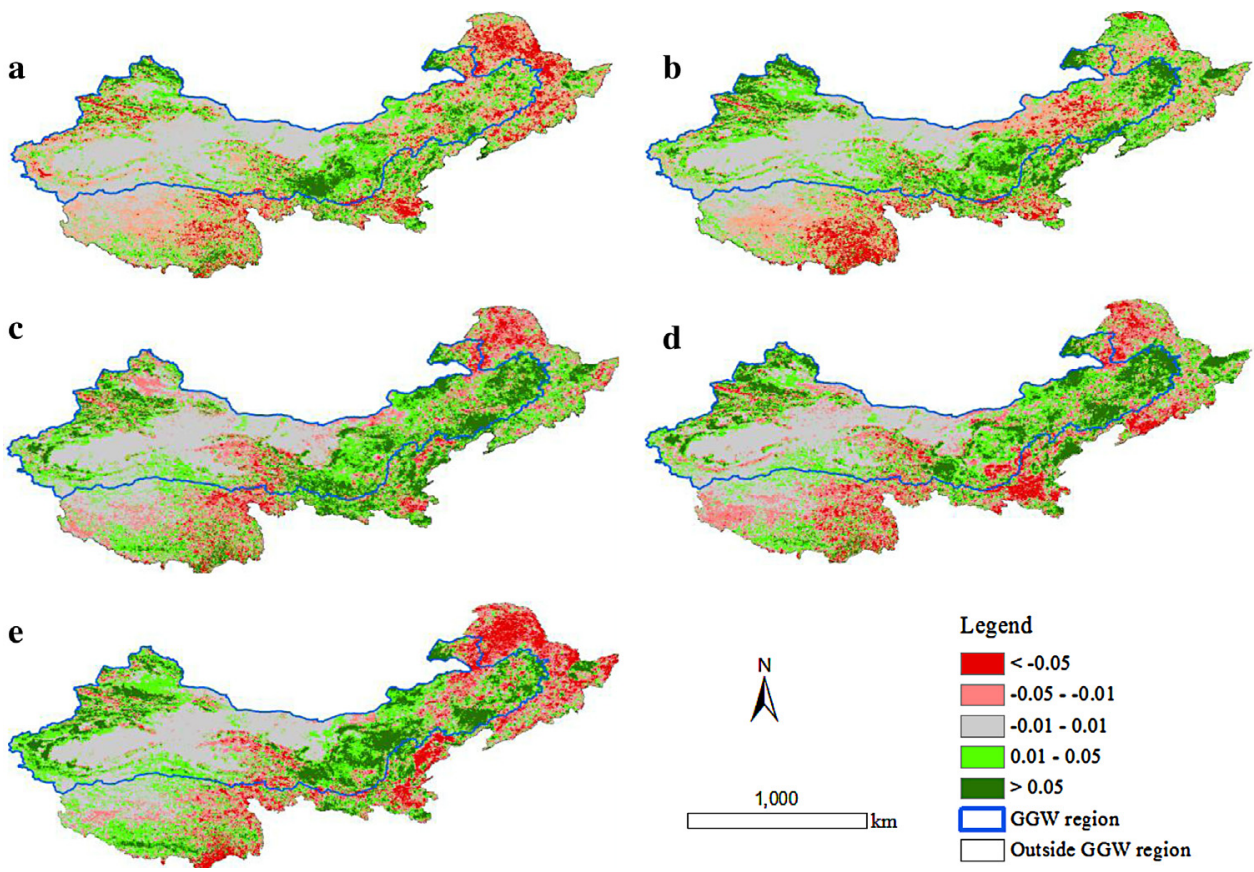

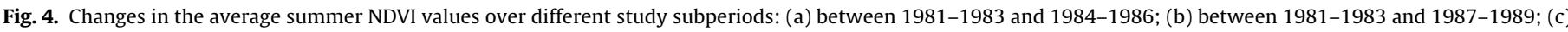
between 1981-1983 and 1990-1992; (d) between 1981-1983 and 1993-1995; (e) between 1981-1983 and 1996-1998.

Spatiotemporal differences in changes in the NDVI values can further confirm the effects of the implementation of the GGW program on vegetation density. To determine the spatial distribution, we calculated 3-year summer average NDVI values for the study period. The average values in the first 3 years $(1981,1982$, and 1983) are regarded as background values because this 3-year data set is the earliest that we could obtain after 1978, when the GGW program was first launched. Thus, changes in NDVI values can be calculated by subtracting this background value from the values of subsequent periods. For example, Fig. 4a shows the differences between the background NDVI values and those from 1984 to 1986 period. In many border regions, the NDVI values for the GGW region increased, while the values outside the region decreased or increased slowly. The differences were significant in the Heilongjiang, Jilin, Liaoning, Qinghai, and Gansu provinces (Figs. 1 and 4a). Mao et al. (2012) drew a similar conclusion about the Heilongjiang and Jilin provinces by integrating AVHRR and MODIS data to monitor changes in NDVI. Similarly, Fig. 4b-e all show differences between the average summer NDVI values inside and outside the GGW region, suggesting that the implementation of the GGW program significantly increased NDVI values (compared to those recorded outside of the GGW region), especially for the time period shown in Fig. 4e.

\section{Changes in NDVI and precipitation}

Here, we have to confront the issue of whether the improved NDVI values were a result of natural factors or the GGW program because the NDVI is an index that integrates the effects of climatic factors and human activities (Duan et al., 2011; Singh et al., 2003). Among the natural factors, some studies suggest that precipitation is one of the most important factors affecting the changes in NDVI values (Mao et al., 2012; Holm et al., 2003). Fig. 5 shows the relationship between precipitation and NDVI values for the 1981-1997 study period. There is no doubt that the precipitation exerted some effect on the change in NDVI. For instance, from 1991 to 1998, the NDVI values decreased significantly outside the GGW region, which was related to the decrease in precipitation (Figs. 3 and 5). In the study region, the annual mean precipitation reached a maximum (251.2 mm) in 1991 and then decreased. Our results, however, indicate that the changes in NDVI values were not strongly correlated with precipitation during that time; the former increased significantly, while the latter showed no specific trend, especially from 1981 to 1988 (Fig. 5).

Human activities, such as overgrazing, over-cultivation, excessive firewood gathering, and irrational use of water resources, are often regarded as factors that cause changes in DSI (Amiraslani and Dragovich, 2011; Chen and Tang, 2005; Portnov and Safriel, 2004). The underlying cause of desertification is the rapidly increasing population, which has surpassed the ecological carrying capacity (D’Odorico et al., 2013; Wang et al., 2013). Thus, a decrease in population pressure may be helpful in decreasing DSI. In this region, however, the increase in NDVI values did not result from a decrease in human pressure, as the population increased continuously. For

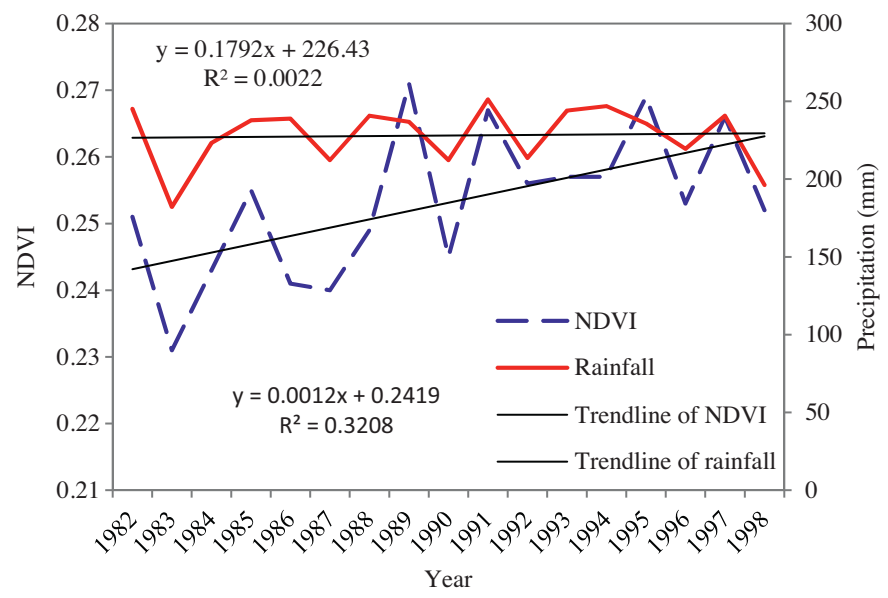

Fig. 5. Relationship between NDVI and precipitation in the study region. 


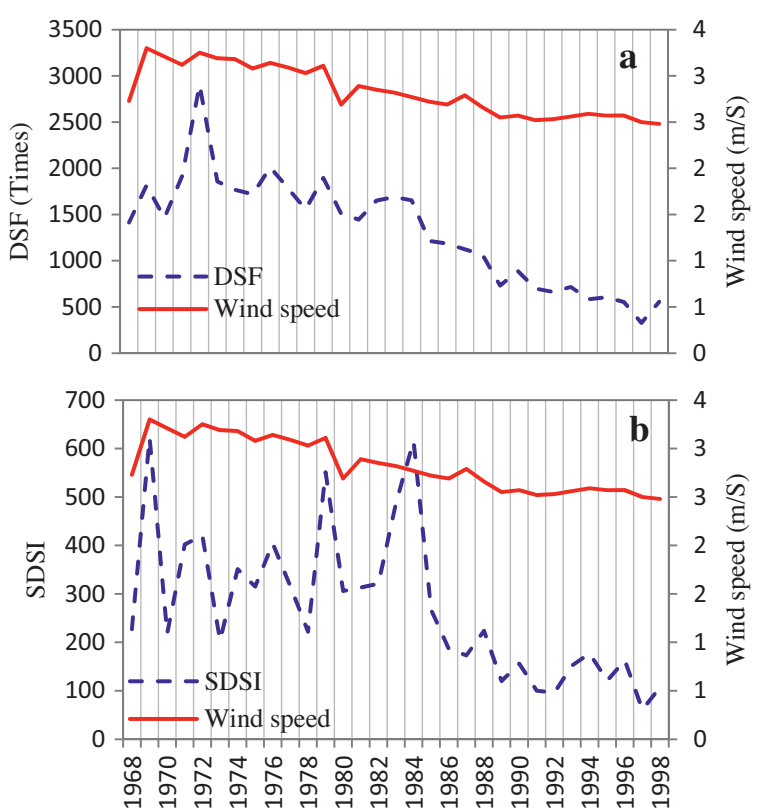

Fig. 6. Changes in wind speed, DSF, and SDSI in the study region, 1968-1988.

instance, populations increased by approximately $26 \%$ and $38 \%$ in Inner Mongolia and Xinjiang, respectively, during the study period 1979-1998. After discounting the effects of changes in human pressure and precipitation, we inferred that the improvement of vegetation density resulted primarily from the implementation of the GGW program during the study period.

\section{Changes in NDVI and DSI}

An increase in vegetation cover may modify the water balance (D'Odorico et al., 2013), fix dunes, and reduce wind speeds (Torita and Satou, 2007), thereby reducing DSI. In the GGW region, for example, observational data show that a greenbelt can reduce wind speed by $22-54 \%$ in downwind areas within 25 times the height of a tree (Zhu, 1985).

Even so, changes in wind speed may largely result from climatic changes rather than an increase in vegetation cover. Thus, our study simply analyzed the effects of changes in wind speed on DSI and DSF in China (Fig. 6). The results indicated that the reduction in wind speed significantly reduced DSF. The effects on DSI, however, were not as significant, especially before 1985 . Thus, we inferred that other factors affected the changes in DSI.

Based on the above discussion, we examined the relationship between the NDVI and DSI values for the period 1982-1998. The results show that the NDVI values had a strongly negative relationship with DSI, with a coefficient of determination $\left(R^{2}\right)$ of about 0.5 (Fig. 7). From this and the preceding discussion, we infer that the GGW program greatly improved the vegetation index, which, in turn, effectively decreased DSI.

As discussed above, some countries have also implemented national programs to combat severe dust storms and desertification effectively. In the United States, for instance, the Great Plains' shelterbelts that reduced soil erosion have been in favor of making the lands available for cultivation and adding to the scenic beauty of the Great Plains landscape (Cook and Cable, 1995; McClure, 1998). In Israel, due to large-scale afforestation programs, the process of desertification did not profoundly affect the Negev region (Portnov and Safriel, 2004). In these programs, improved vegetation effectively reduced DSI through measures including aerial seeding to cover wide swaths of land where the soil is less arid, offering cash incentives to farmers to plant trees and shrubs in

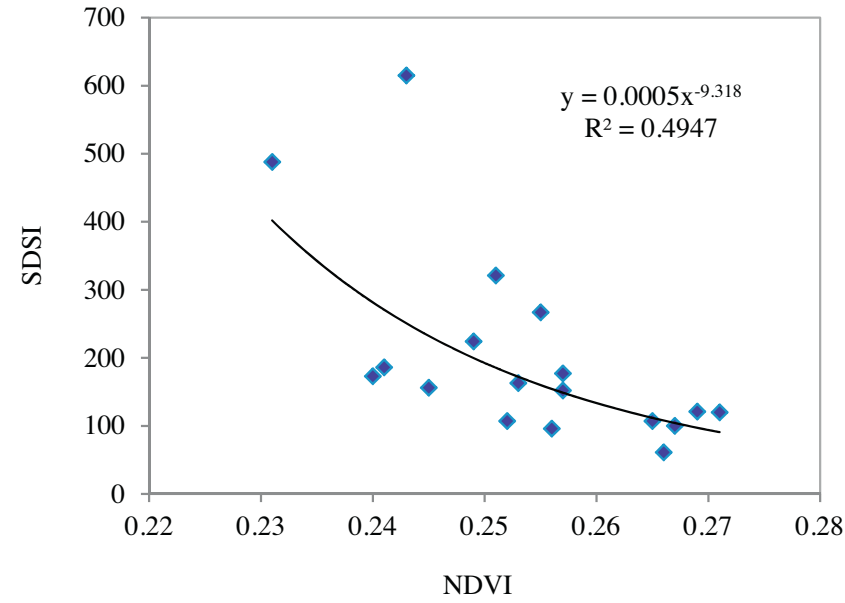

Fig. 7. Relationship between NDVI and SDSI during 1982-1998. NDVI values refer to the previous year's data because vegetation components (roots, humus, etc.) can influence the soil texture the spring months of the following year (Xu et al., 2006). In China, most dust storm activity occurs in the spring.

more arid areas, and building up forest networks in croplands, on plains, and in oases (Li et al., 2012). Of course, other methods such as windbreaks, stubble mulching, contour-plowing, and notillage practices have also been incorporated into strategies used to combat desertification to reduce the amount of wind and water erosion (Hooke and Sandercock, 2012; McClure, 1998).

\section{Conclusions}

By integrating AVHRR and weather station data, this study has examined the effects of the implementation of the country's GGW program on NDVI values. The following conclusions were reached. In the GGW region, the NDVI values from 1981 to 1998 increased steadily, while the values varied dramatically outside the GGW region during this period. Furthermore, in many border areas (between inside and outside of the GGW region), the values in the GGW region increased significantly, while values outside of the region increased slowly or decreased. Thus, the implementation of the GGW program was observed to have improved vegetation density.

By examining the relationship between precipitation and NDVI values, we found that the changes in NDVI were not strongly correlated with precipitation from 1981 to 1997 in the GGW region. During this time, NDVI increased significantly, while precipitation showed no specific trend, especially from 1981 to 1988 . These results further verify that the GGW program improved vegetation in the study area.

DSI measurements were used to quantify dust activities; the calculations incorporated the frequency, visibility, and duration of dust events. From 1971 to 1984, DSI varied greatly, and it has decreased dramatically since 1985 . In contrast, DSF has decreased continuously since 1971 .

Finally, the results demonstrated that NDVI had a strong negative correlation with DSI, with an $R^{2}$ value of 0.5 for the $1982-1998$ period. From this result, we infer that the implementation of the GGW program has effectively decreased DSI by improving the vegetation conditions. This conclusion is contrary to conventional studies that often use DSF to measure dust activity.

\section{Acknowledgments}

We acknowledge the use of the NDVI data from Global Inventory Modeling and Mapping Studies (GIMMS) (http://glcf.umd.edu/ 
data/gimms/) and the dust storm and climate data from the China Meteorological Data Sharing System (http://cdc.cma.gov.cn/ cdc_en/home.dd). This work was supported by the Natural Science Foundation of China (Grant No. 91325302, 41161140352, 41271119). Valuable comments and suggestions from anonymous reviewers are greatly appreciated.

\section{Appendix A. Supplementary data}

Supplementary data associated with this article can be found, in the online version, at http://dx.doi.org/10.1016/j.landusepol. 2014.10.017.

\section{References}

Akhtar-schuster, M., Thomas, R.J., Stringer, L.C., et al., 2011. Improving the enabling environment to combat land degradation: institutional, financial, legal and science-policy challenges and solutions. Land Degrad. Dev. 22, 299312.

Amiraslani, F., Dragovich, D., 2011. Combating desertification in Iran over the last 50 years: an overview of changing approaches. J. Environ. Manag. 92, 1-13.

Anyamba, A., Tucker, C.J., 2005. Analysis of Sahelian vegetation dynamics using NOAA-AVHRR NDVI data from 1981-2003. J. Arid Environ. 63, 596614.

Chen, Y., Tang, H., 2005. Desertification in North China: background, anthropldenci impacts and failures in combating it. Land Degrad. Dev. 16, 367-376.

Cook, P.S., Cable, T.T., 1995. The scenic beauty of shelterbelts on the Great Plains. Landsc. Urban Plan. 32, 63-69.

D’Odorico, P., Bhattachan, A., Davis, K.F., Ravi, S., Runyan, C.W., 2013. Global desertification: drivers and feedbacks. Adv. Water Resour. 51, 326-344.

Duan, H., Yan, C., Tsunekawa, A., Song, X., Li, S., Xie, J., 2011. Assessing vegetation dynamics in the Three-North Shelter Forest region of China using AVHRR NDVI data. Environ. Earth Sci. 64, 1011-1020.

Fang, J., Chen, A., Peng, C., Zhao, S., Ci, L., 2001. Changes in forest biomass carbon storage in China between 1949 and 1998. Science 292, 2320-2322.

Feng,Z., Zhang,P., Yang,Y., 2003. The scale of land conversion from farmland to forest or grassland, the grain response to it, and the relevant proposals in Northernwest China. Geogr. Res. 22 (1), 105-113 (in Chinese).

Fensholt, R., Rasmussen, K., Nielsen, T.T., Mbow, C., 2009. Evaluation of earth observation based long term vegetation trends-intercomparing NDVI time series trend analysis consistency of Sahel from AVHRR GIMMS, Terra MODIS and SPOT VGT data. Remote Sens. Environ. 113, 1886-1898.

Fensholt, R., et al., 2012. Greenness in semi-arid areas across the globe 1981-2007-an earth observing satellite based analysis of trends and drivers. Remote Sens. Environ. 121, 144-158.

Funk, C.C., Brown, M.E., 2006. Intra-seasonal NDVI change projections in semi-arid Africa. Remote Sens. Environ. 101, 249-256.

Glenna, E., Smith, M.S., Squires, V., 1998. On our failure to control desertification: implications for global change issues, and a research agenda for the future. Environ. Sci. Policy 1, 71-98.

Holm, A.M., Cridland, S.W., Roderick, M.L., 2003. The use of time-integrated NOAA NDVI data and rainfall to assess landscape degradation in the arid shrubland of Western Australia. Remote Sens. Environ. 85, 145-158.

Hooke, J., Sandercock, P., 2012. Use of vegetation to combat desertification and land degradation: recommendations and guidelines for spatial strategies in Mediterranean lands. Landsc. Urban Plan. 107, 389-400.

Huang, J., Ge, J., Weng, F., 2007. Detection of Asia dust storms using multisensor satellite measurements. Remote Sens. Environ. 110, 186-191.

Li, M., Liu, A., Zou, C., Xu, W., Shimizu, H., Wang, K., 2012. An overview of the ThreeNorth Shelterbelt project in China. For. Stud. China 14 (1), 70-79.

Mao, D., Wang, Z., Luo, L., Ren, C., 2012. Integrating AVHRR and MODIS data to monitor NDVI changes and their relationships with climatic parameters in Northeast China. Int. J. Appl. Earth Obs. Geoinform. 18, 528-536.
McClure, B.C., 1998. Polices related to combating desertification in the United States of America. Land Degrad. Dev. 9, 383-392.

McKendry, I.G., Hacker, J.P., Stull, R., Sakiyama, S., Mignaca, D., Reid, K., 2001. Long range transport of Asian dust to the Lower Fraser Valley, British Columbia, Canada. J. Geophys. Res. 106 (D16), 18361-18370.

McTainsh, G., Chan Y.-C., McGowan, H., Leys, J., Tews, K., 2005. The 23rd October 2002 dust storm in eastern Australia: characteristics and meteorological conditions. Atmos. Environ. 39, 1227-1236

McTainsh, G.H., Leys, J.F., O'Loingsigh, T., Strong, C.L., 2011. Wind erosion and land management in Australia during 1940-1949 and 2000-2009. In: Report Prepared for the Australian Government Department of Sustainability, Environment, Water, Population and Communities on Behalf of the State of the Environment 2011 Committee. DSEWPaC: 45, Canberra.

O'Loingsigh, T., McTainsh, G.H., Tews, E.K., Strong, C.L., Leysb, J.F., Shinkfield, P., Tapper, N.J., 2014. The Dust Storm Index (DSI): a method for monitoring broadscale wind erosion using meteorological records. Aeolian Res. 12, 29-40.

Parungo, F., Li, Z., Li, X., Yang, D., Harris, J., 1994. Gobi dust storms and The Great Green Wall. Geophys. Res. Lett. 21 (11), 999-1002.

Piao, S., Wang, X., Ciais, P., Zhu, B., Wang, T., Liu, J., 2011. Changes in satellite-derived vegetation growth trend in temperate and boreal Eurasia from 1982 to 2006 Glob. Change Biol. 17, 3228-3239.

Portnov, B.A., Safriel, U.N., 2004. Combating desertification in the Negev: dryland agriculture vs. dryland urbanization. J. Arid Environ. 56, 659-680.

Prospero, J.M., 1999. Long-range transport of mineral dust in the global atmosphere: impact of African dust on the environment of the southeastern United States. Proc. Natl. Acad. Sci. U. S. A. 96, 3396-3403.

Prospero, J.M., Lamb, P.J., 2003. African droughts and dust transport to the Caribbean: climate change implications. Science 302, 1024-1027.

Schepanski, Tegen, I., Macke, A., 2012. Comparison of satellite based observations of Saharan dust source areas. Remote Sens. Environ. 123, 90-97.

Senay, G.B., Elliott, R.L., 2000. Combining AVHRR-NDVI and land use data to describe temporal and spatial dynamics of vegetation. Forest Ecol. Manag. 128, 83-91.

Singh, D., et al., 2003. An approach to correlate NDVI with soil colour for erosion process using NOAA/AVHRR data. Adv. Space Res. 33, 328-332.

Song, Z., 2004. A numerical simulation of dust storms in China. Environ. Model. Softw. 9, 141-151.

Speer, M.S., 2013. Dust storm frequency and impact over Eastern Australia determined by state of Pacific climate system. Weather Clim. Extremes 2, 16-21.

Tan, M., Li, X., Xin, L., 2014. Intensity of dust storms in China from 1980 to 2007: a new definition. Atmos. Environ. 85, 215-222.

Torita, H., Satou, H., 2007. Relationship between shelterbelt structure and mean wind reduction. Agric. Forest Meteorol. 145, 186-194.

Uno, I., Eguchi, K., Yumimoto, K., Takemura, T., Shimizu, A., Uematsu, M., Zhaoyan Liu, Z., Hara, Y., Sugimoto, N., 2009. Asian dust transported one full circuit around the globe. Nat. Geosci. 2, 557-560.

Wang, X., Lu, C., Fang, J., Shen, Y., 2007. Implications for development of grain-forgreen policy based on cropland suitability evaluation in desertification-affected north China. Land Use Policy 24, 417-424.

Wang, X.M., Zhang, C.X., Hasi, E., Dong, Z.B., 2010. Has the Three Norths Forest Shelterbelt Program solved the desertification and dust storm problems in arid and semiarid China? J. Arid Environ. 74, 13-22.

Wang, F., Pan, X., Wang, D., Shenc, C., Lu, Q., 2013. Combating desertification in China: past, present and future. Land Use Policy 31, 311-313.

Xu, X., Levy, J.K., Lin, Z., Hong, C., 2006. An investigation of sand-dust storm events and land surface characteristics in China using NOAA NDVI data. Glob. Planet. Change 52, 182-196.

Zhang, P., Shao, G., Zhao, G., Master, D.C.L., Parker Jr., G.R., Dunning, J.B., Li, Q., 2000. China's forest policy for the 21 st century. Science 288, 2135-2136.

Zheng, X., Zhu, J., 2013. Estimation of shelter forest area in Three-North Shelter Forest Program region based on multi-sensor remote sensing data. Chin. J. Appl. Ecol. $24(8), 2257-2264$.

Zhu, J., 1985. Natural Resources and Comprehensive Zoning of Agricultural Region. Chinese Forest Press, Beijing.

Zhu, J., Zhou, X., Hu, J., 2004. Thoughts and views about the three north shelterbelt program. J. Nat. Res. 19 (1), 79-85 (in Chinese). 